\title{
Deinococcus geothermalis sp. nov. and Deinococcus murrayi sp. nov., Two Extremely Radiation-Resistant and Slightly Thermophilic Species from Hot Springs
}

\author{
ANA CRISTINA FERREIRA, ${ }^{1}$ M. FERNANDA NOBRE, ${ }^{2}$ FRED A. RAINEY, ${ }^{3} \dagger$ MANUEL T. SILVA, ${ }^{4}$ \\ ROBIN WAIT, ${ }^{5}$ JUTTA BURGHARDT, ${ }^{3}$ ANA PAULA CHUNG,${ }^{1}$ AND MILTON S. DA COSTA ${ }^{1 *}$ \\ Departamento de Bioquímica ${ }^{1}$ and Departamento de Zoologia, ${ }^{2}$ Universidade de Coimbra, 3000 Coimbra, and \\ Centro de Citologia Experimental, Universidade do Porto, 4150 Porto, ${ }^{4}$ Portugal; Deutsche Sammlung von \\ Mikroorganismen und Zellkulturen, 38124 Braunschweig, Germany ${ }^{3}$; and Centre for Applied \\ Microbiology \& Research, Porton Down, Salisbury, Wiltshire SP4 OJG, United Kingdom ${ }^{5}$
}

\begin{abstract}
Strains of Deinococcus geothermalis sp. nov. were isolated from the hot spring and runoff at Agnano, Naples, Italy, and from the hot spring at São Pedro do Sul in central Portugal, while strains of Deinococcus murrayi sp. nov. were isolated from the hot springs at São Pedro do Sul, São Gemil, and Alcafache in central Portugal. The strains of $D$. geothermalis and $D$. murrayi produce orange-pigmented colonies and have an optimum growth temperature of about 45 to $50^{\circ} \mathrm{C}$. The type strains of the two new species are extremely gamma radiation resistant. The fatty acids of these new species are primarily branched-chain fatty acids. The two new species can be distinguished from each other by the lower $\mathrm{pH}$ range of $D$. geothermalis than of $D$. murrayi, by their fatty acid compositions, and by several biochemical parameters, including the ability of $D$. geothermalis to grow in minimal medium without yeast extract. 16S rRNA gene sequencing also showed that the isolates constitute two species and that these species are distinct from the other species of the genus Deinococcus. The type strain of D. geothermalis is AG-3a (= DSM 11300), and the type strain of D. murrayi is ALT-1b (= DSM 11303).
\end{abstract}

The genus Deinococcus includes the species Deinococcus radiodurans, Deinococcus proteolyticus, Deinococcus radiophilus, and Deinococcus radiopugnans. The species Deinococcus erythromyxa was also included in this genus as a species incertae sedis by Brooks and Murray (3). The rod-shaped organisms of the species Deinococcus grandis are very closely related to the species of the genus Deinococcus, but were classified in the genus Deinococcus primarily on the basis of morphology (36). Recently, the type strains of these species were subjected to a complete 16S ribosomal DNA (rDNA) sequence analysis, which resulted in the reclassification of Deinococcus grandis and Deinococcus erythromyxa (41). The species Deinococcus grandis, despite its rod-shaped morphology, falls within the radiation of the genus Deinococcus and for this reason was classified as Deinococcus grandis. The species Deinococcus erythromyxa was known by Brooks and Murray (3) to have characteristics that were different from those of the other species of Deinococcus, and subsequent studies confirmed its chemotaxonomic distinctiveness, which reinforced the need for reclassification of this species (12). The species Deinococcus erythromyxa has been found to be phylogenetically very closely related to the gram-positive species Kocuria rosea, but due to the low DNA-DNA hybridization values between the two species, Kocuria erythromyxa was maintained as a separate species (41).

The species of the genus Deinococcus are strictly aerobic, have optimum growth temperatures in the range from 25 to $35^{\circ} \mathrm{C}$, produce reddish colonies, generally stain gram positive, have ornithine in the peptidoglycan, lack teichoic acids, possess menaquinone 8 as the major respiratory quinone, and are

\footnotetext{
* Corresponding author. Mailing address: Departamento de Bioquímica, Universidade de Coimbra, Apartado 3126, 3000 Coimbra, Portugal. Phone: 351-39-24024. Fax: 351-39-26798. E-mail: milton @cygnus.ci.uc.pt.

$\uparrow$ Present address: Department of Microbiology, Louisiana State University, Baton Rouge, LA 70803.
}

phylogenetically related to the thermophilic species of the genera Thermus and Meiothermus $(13,17,35,53)$. The most striking characteristic of the species of this genus is their extreme resistance to UV and gamma radiation. For this reason UV or gamma radiation has been used to isolate most of the organisms of the genus Deinococcus from foods, feces, soils, and dust $(1,8,19,22,24,28,36)$. The small number of strains isolated without irradiation of samples demonstrates that the extreme radiation resistance of the organisms is not a result of selection of resistant strains by irradiation, but is a normal characteristic, which is believed to be related to the desiccation resistance of these organisms (29). Gamma irradiation of exponential-phase cultures of strains of Deinococcus radiodurans shows that there is virtually no decrease in viable counts at doses of 4 to $5 \mathrm{kGy}$ (33), and survivors are routinely recovered from cultures exposed to as much as $20 \mathrm{kGy}(1,20)$. The extreme gamma radiation resistance of the species of this genus is due to a very efficient repair system for double-strand breaks in the DNA, while the UV resistance is conferred by two nucleotide excision repair pathways acting simultaneously (31).

We recently isolated several orange-pigmented strains with spherical cells from hot springs and hot spring runoffs with temperatures ranging from 48 to $57^{\circ} \mathrm{C}$ in central Portugal and from Agnano, Naples, Italy. The isolates from Agnano and the first isolates from Portugal were obtained from nonirradiated samples. Later, samples from the Portuguese hot springs were irradiated, which led to the isolation of additional strains. Biochemical, chemotaxonomic, and morphological characteristics, gamma radiation resistance, and phylogenetic analysis show that the isolates represent two new species of the genus Deinococcus with optimum growth temperatures of about 45 to $50^{\circ} \mathrm{C}$, for which we propose the names Deinococcus geothermalis and Deinococcus murrayi.

\section{MATERIALS AND METHODS}

Isolation and bacterial strains. Strain $A L T-1 b^{T}$ was isolated from the hot spring at Alcafache in central Portugal, strain RSG-1.2 was isolated from São 
Gemil in central Portugal, and strains RSPS-2a, RSPS-5a, RSPS-5c, and RSPS-7a were isolated from São Pedro do Sul in central Portugal. Strains $A G-3 a^{T}, A G-4 a, A G-5 a, A G-6 a$, and AG-7a were isolated at the Termi di Agnano, Naples, Italy. The strains whose designations begin with $\mathrm{R}$ were isolated after irradiation of samples with a cobalt 60 source at a dose of $8.06 \mathrm{kGy}$ and a rate of $1.5 \mathrm{kGy} \mathrm{h}^{-1}$. Water samples were transported without temperature control and were filtered through membrane filters (Gelman type GN-6; pore size, $0.45 \mu \mathrm{m}$; diameter, $47 \mathrm{~mm}$ ). The filters were placed on the surfaces of agar plates; the plates were wrapped in plastic bags and incubated at $45^{\circ} \mathrm{C}$ for up to 7 days. The strains whose designations begin with AG- and strains ALT-1b ${ }^{\mathrm{T}}$, RSPS-2a, and RSG-1.2 were isolated on plates containing solidified Thermus medium (54), while strains RSPS-5a, RSPS-5c, and RSPS-7a were isolated from plates containing $\mathrm{R}_{3} \mathrm{~A}$ medium (44). Cultures were purified by subculturing and were kept at $-80^{\circ} \mathrm{C}$ in Thermus medium containing $15 \%$ glycerol.

Deinococcus radiodurans DSM $20539^{\mathrm{T}}$, Deinococcus (Deinobacter) grandis DSM $3963^{\mathrm{T}}$, Deinococcus proteolyticus DSM $20540^{\mathrm{T}}$ and Deinococcus radiophilus DSM $20551^{\mathrm{T}}$ were obtained from the Deutsche Sammlung von Mikroorganismen und Zellkulturen, Braunschweig, Germany; Deinococcus radiopugnans ATCC $19172^{\mathrm{T}}$ was obtained from the American Type Culture Collection, Rockville, Md. These type strains were maintained in growth medium 53 as described in the DSM Catalogue of Strains $(10)$ at $-80^{\circ} \mathrm{C}$ in the presence of $15 \%$ glycerol.

Morphological, biochemical, and tolerance characteristics. Cell morphology and motility were examined by phase-contrast microscopy during the exponential growth phase in Degryse medium 162. Cell dimensions were determined by using an ocular micrometer calibrated with a stage micrometer. Catalase activity was determined by the formation of bubbles with a $3 \%$ hydrogen peroxide solution; oxidase activity was determined by the oxidation of $1 \%$ aqueous tetramethyl-pphenylenediamine on filter paper at room temperature. The presence of spores was determined after 7 days of growth on Degryse medium 162 without tryptone to which $10 \mathrm{~g}$ of soluble starch per liter was added. Biochemical and tolerance tests were performed at $47^{\circ} \mathrm{C}$ for up to 7 days as described previously $(27,46)$ in liquid or solidified Degryse medium 162 at the appropriate $\mathrm{pH}$ containing $2.5 \mathrm{~g}$ of yeast extract per liter and $2.5 \mathrm{~g}$ of tryptone per liter (9). The $\mathrm{pH}$ range for growth was examined in this medium by using $12 \mathrm{mM}$ citrate-phosphate buffer between $\mathrm{pH} 4.0$ and 5.0, $12 \mathrm{mM}$ MES [2-( $N$-morpholino)ethanesulfonic acid] between $\mathrm{pH} 5.5$ and $6.5,12 \mathrm{mM}$ HEPES [ $N$-(2-hydroxyethyl)piperazine- $N{ }^{\prime}-(2-$ ethanesulfonic acid)] between $\mathrm{pH} 7.0$ and 8.5 , and $12 \mathrm{mM}$ CAPSO [3-(cyclohexylamino)-2-hydroxy-1-propanesulfonic acid] between $\mathrm{pH} 9.0$ and 10.5. The temperature range for growth of strains AG-3a ${ }^{\mathrm{T}}, \mathrm{AG}-5 \mathrm{a}$, and RSPS-2a was examined in medium adjusted to $\mathrm{pH} 6.5$, while the medium for strains ALT- $1 \mathrm{~b}^{\mathrm{T}}$, RSG-1.2, and RSPS-7a was adjusted to $\mathrm{pH} 8.0$ before autoclaving. Growth was examined by measuring the turbidity (at $610 \mathrm{~nm}$ ) of cultures grown in $300-\mathrm{ml}$ metal-capped Erlenmeyer flasks containing $100 \mathrm{ml}$ of medium in a reciprocal water bath shaker.

Single-carbon-source assimilation tests were performed in a minimal medium composed of Degryse basal salts medium 162 containing $0.1 \mathrm{~g}$ of yeast extract per liter to which filter-sterilized carbon sources $\left(2.0 \mathrm{~g} \mathrm{liter}^{-1}\right)$ and ammonium sulfate $\left(0.5 \mathrm{~g} \mathrm{liter}^{-1}\right)$ were added. Growth was examined by measuring the turbidity, for up to 7 days, of cultures incubated at $47^{\circ} \mathrm{C}$ in 20 -ml screw-cap tubes containing $10 \mathrm{ml}$ of medium. Positive and negative control cultures were grown in Degryse medium 162 and in minimal medium containing only ammonium sulfate and yeast extract.

Electron microscopy. Cultures were grown at $47^{\circ} \mathrm{C}$ for $24 \mathrm{~h}$ in Degryse medium 162 , adjusted to the appropriate $\mathrm{pH}$ for each species, washed by centrifugation, prefixed for $16 \mathrm{~h}$ at room temperature in $2.5 \%$ glutaraldehyde in $0.1 \mathrm{M}$ cacodylate buffer at $\mathrm{pH} 7.2$, washed in the same buffer, and fixed in $1 \% \mathrm{OsO}_{4}$ in Veronal-acetate buffer (pH 6.2) containing $10.0 \mathrm{mM} \mathrm{NaCl}$ and $10.0 \mathrm{mM} \mathrm{CaCl}_{2}$ for $16 \mathrm{~h}$ at room temperature (48). The cells were washed in water and postfixed for $30 \mathrm{~min}$ at room temperature in $1.0 \%$ uranyl acetate. The pellets were dehydrated with ethanol and embedded in Epon. Ultrathin sections were double contrasted with uranyl-lead (48) or by a modification of the Thiéry method for detection of periodic acid-Schiff-positive material indicative of polysaccharidecontaining material (49)

Radiation resistance. Bacteria were grown in the appropriate liquid medium until the exponential phase of growth, washed once by centrifugation at $4^{\circ} \mathrm{C}$, and resuspended to a concentration of $1 \times 10^{7}$ to $1 \times 10^{8} \mathrm{CFU} / \mathrm{ml}$ in $0.067 \mathrm{M}$ potassium phosphate buffer at $\mathrm{pH} 7.0$. The suspensions were divided into $5-\mathrm{ml}$ aliquots and exposed to a cobalt 60 source with a dose rate of $1.34 \mathrm{kGy} \mathrm{h}^{-1}(1$ $\mathrm{kGy}=1 \times 10^{5}$ rads) at room temperature. At appropriate intervals, $0.1 \mathrm{ml}$ of each suspension was removed and diluted in the same buffer, and 20- $\mu$ l portions of several dilutions were placed, in triplicate, on plates of Degryse medium 162 adjusted to the optimum $\mathrm{pH}$ for the growth of each organism. The plates containing the type strain of Deinococcus radiodurans were incubated at $30^{\circ} \mathrm{C}$, the plates containing strains AG- $3 \mathrm{a}^{\mathrm{T}}$ and $\mathrm{ALT}-1 \mathrm{~b}^{\mathrm{T}}$ were incubated at $47^{\circ} \mathrm{C}$, and the CFU were counted daily for up to 15 days. Viability was assessed by using unirradiated suspensions of each strain maintained under the same conditions.

Peptidoglycan analysis and polar lipid, lipoquinone, and fatty acid compositions. Preparation of peptidoglycan and determination of peptidoglycan structure were carried out as described by Schleifer and Kandler (47). Freeze-dried cells $\left(1 \mathrm{mg}\right.$ ) were hydrolyzed in $0.2 \mathrm{ml}$ of $4 \mathrm{~N} \mathrm{HCl}$ at $100^{\circ} \mathrm{C}$ for $16 \mathrm{~h}$ (total hydrolysate) and for $45 \mathrm{~min}$ (partial hydrolysate). Diamino acid contents were determined by one-dimensional thin-layer chromatography on cellulose plates with a methanol-pyridine-water- $10 \mathrm{~N} \mathrm{HCl} \mathrm{(32:4:7:1,} \mathrm{vol/vol/vol/vol)} \mathrm{solvent} \mathrm{sys-}$ tem. Amino acids and peptides were identified after two-dimensional thin-layer chromatography performed with the solvent systems of Schleifer and Kandler (47) by their mobilities and staining properties with ninhydrin.

The cultures used for polar lipid analysis were grown in 1-liter Erlenmeyer flasks containing $200 \mathrm{ml}$ of Degryse medium 162 at $47^{\circ} \mathrm{C}$ in a reciprocal water bath shaker until the late exponential phase of growth. Harvesting of the cultures, extraction of the lipids, and two-dimensional thin-layer chromatography were performed as described previously $(11,37)$.

Lipoquinones were extracted from freeze-dried cells and were purified by thin-layer chromatography as described by Tindall (52). The lipoquinones were separated with a Gilson high-performance liquid chromatograph by using a reverse-phase (RP18) Spherisorb S5 ODS2 column and methanol-heptane (10:2, $\mathrm{vol} / \mathrm{vol}$ ) as the mobile phase and were detected at $269 \mathrm{~nm}$.

The cultures for fatty acid analysis were grown on Degryse medium 162 plates in sealed plastic bags submerged in a water bath at $47^{\circ} \mathrm{C}$ for the strains of the new species and at $30^{\circ} \mathrm{C}$ for the type strains of the previously described Deinococcus spp. Fatty acid methyl esters were obtained from fresh wet biomass by saponification, methylation, and extraction as described previously (23). Fatty acid methyl esters were separated with a Hewlett-Packard model 5890 gas chromatograph equipped with a flame ionization detector fitted with a $5 \%$ phenyl-methyl silicone capillary column (type Ultra 2; $0.2 \mathrm{~mm}$ by $25 \mathrm{~m}$; Hewlett-Packard). The carrier gas was high-purity $\mathrm{H}_{2}$; the column head pressure was $60 \mathrm{kPa}$; the septum purge rate was $5 \mathrm{ml} \mathrm{min}^{-1}$; the column split ratio was $55: 1$; and the injection port temperature was $300^{\circ} \mathrm{C}$. The temperature of the oven was programmed to increase from 170 to $270^{\circ} \mathrm{C}$ at a rate of $5^{\circ} \mathrm{C} \mathrm{min}{ }^{-1}$. Identification and quantification of the fatty acid methyl esters, as well as the numerical analysis of the fatty acid profiles, were performed by using the standard MIS Library Generation software (Microbial ID, Inc., Newark, Del.).

Gas chromatography-mass spectrometry. The identities of the fatty acid methyl esters were confirmed by gas chromatography-mass spectrometry performed with a model MS80 RFA mass spectrometer (Kratos, Ltd., Manchester, United Kingdom) interfaced to a Carlo Erba model 5160 capillary gas chromatograph fitted with a type BPX-5 column $(0.2 \mathrm{~mm}$ by $25 \mathrm{~m}$; SGE, Ltd., Milton Keynes, United Kingdom) which terminated in a combined electron ionizationchemical ionization source. The carrier gas was helium at a flow rate of $0.7 \mathrm{ml}$ $\mathrm{min}^{-1}$. The injector and interface ovens were maintained at $250^{\circ} \mathrm{C}$, and samples, dissolved in trimethylpentane, were introduced with a 5- $\mu$ l syringe through a septumless JADE value injection system (Jade Systems, Inc., Austin, Tex.). A splitless injection technique was used (30-s splitless time) at an initial oven temperature of $80^{\circ} \mathrm{C}$. One minute after injection the column oven temperature was programmed to increase to $200^{\circ} \mathrm{C}$ at a rate of $40^{\circ} \mathrm{C} \mathrm{min}-1$ and then to increase from 200 to $250^{\circ} \mathrm{C}$ at a rate of $4^{\circ} \mathrm{C} \mathrm{min}-1$. Spectra were recorded under the control of a Sun Microsystems SPARCstation IPX by using Mach-3 instrument control and data-processing software (Kratos, Ltd.). The instrument was operated at 1,000 resolution and was scanned at $0.6 \mathrm{~s}$ per decade of mass over the range from 550 to 40 . Electron ionization spectra were recorded at an ionization energy of $70 \mathrm{eV}$ and a trap current of $100 \mathrm{~mA}$ at a source temperature of $250^{\circ} \mathrm{C}$.

Determination of $\mathbf{G}+\mathbf{C}$ content of DNA. The DNA was isolated as described by Cashion et al. (7). The $\mathrm{G}+\mathrm{C}$ content of the DNA was determined by highperformance liquid chromatography as described by Mesbah et al. (30).

$16 S$ rDNA sequence determination and phylogenetic analyses. Genomic DNA extraction, PCR amplification of the 16S rDNA, and sequencing of the PCR products were carried out as described previously (43). Sequence reaction products were electrophoresed by using a model 373A automated sequencer (Applied Biosystems, Foster City, Calif.). The ae2 editor (26) was used to align the 16S rDNA sequences obtained in this study with the previously determined Deinococcus and Thermus sequences available from the public databases. The method of Jukes and Cantor (21) was used to calculate evolutionary distances. Phylogenetic dendrograms were generated by using various treeing algorithms contained in the PHYLIP package (14)

Nucleotide sequence accession numbers. The $16 \mathrm{~S}$ rDNA sequences determined in this study have been deposited in the EMBL database under the following accession numbers: strain AG-3a ${ }^{\mathrm{T}}$, Y13038; strain AG-5a, Y13039; strain RSPS-2a, Y13040; strain ALT-1b ${ }^{\mathrm{T}}$, Y13041; strain RSG-1.2, Y13042; and strain RSPS-7a, Y13043. The strain designations and accession numbers of the 16S rDNA reference sequences used in the phylogenetic analyses are as follows: Deinococcus grandis DSM 3963 ${ }^{\mathrm{T}}$, Y11329; Deinococcus proteolyticus DSM 20540 ${ }^{\mathrm{T}}$, Y11331; Deinococcus radiodurans DSM 20539 , Y11332; Deinococcus radiophilus DSM 20551 ${ }^{\mathrm{T}}$, Y11333; Deinococcus radiopugnans ATCC $19172^{\mathrm{T}}$, Y11334; Meiothermus chliarophilus DSM 9957 ${ }^{\mathrm{T}}$, X84212; Meiothermus ruber ATCC 35948 ${ }^{\mathbf{T}}$, L09672; Thermus aquaticus ATCC 25104 ${ }^{\mathrm{T}}$, L09663; and Thermus thermophilus ATCC $27634^{\mathrm{T}}$, M26923.

\section{RESULTS}

Isolation of strains, growth, and morphological and biochemical characteristics. The strains whose designations begin with AG- were isolated from hot springs and runoffs with temperatures ranging from 45 to $57^{\circ} \mathrm{C}$ and with $\mathrm{pH}$ values of 

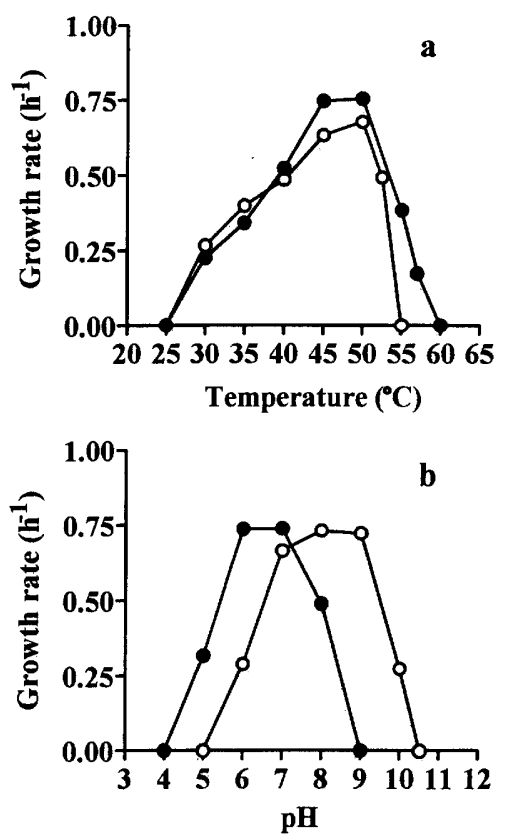

FIG. 1. Effect of temperature (a) and $\mathrm{pH}$ (b) on the growth of strain AG-3a $\mathrm{a}^{\mathrm{T}}$ (•) and strain ALT- $1 b^{\mathrm{T}}(\mathrm{O}$.

about 6.4 to 6.9 at the Termi di Agnano near Naples, Italy. The hot spring sites at São Gemil, Alcafache, and São Pedro do Sul in central Portugal had alkaline $\mathrm{pH}$ values ranging from 8.6 to 8.9 and temperatures of 48,50 , and 50 to $55^{\circ} \mathrm{C}$, respectively. The strains from Agnano and the initial isolates from Alcafache were recovered from samples of water and biofilms without irradiation, but the other samples from Portugal were subsequently irradiated.

The isolates had optimum growth temperatures of about 45 to $50^{\circ} \mathrm{C}$ (Fig. 1a), but very different $\mathrm{pH}$ ranges; strains $\mathrm{AG}-3 \mathrm{a}^{\mathrm{T}}$, AG-5a, and RSPS-2a had a pH range of about 4.5 to 8.5 , with an optimum $\mathrm{pH}$ for growth of 6.5 , while strains ALT $-1 b^{\mathrm{T}}$, RSG-1.2, and RSPS-7a had a pH range of about 5.5 to 10.0 , with an optimum pH of about 8.0 (Fig. 1b).

All of the isolates formed orange-pigmented spherical cells that stained gram positive, and cells dividing as tetrads were very common in both species. Transmission electron microscopy showed that the cytoplasmic membrane of strain ALT$1 \mathrm{~b}^{\mathrm{T}}$ had a typical three-layered profile with a symmetric geometry (Fig. 2a). The cell wall was multilayered; the innermost layer (L1) had a loose appearance, but remained bound to the outer wall components upon plasmolysis of the cells (data not shown). The intermediate layer (L2) was electron dense and was similar to the peptidoglycan layer in gram-positive bacteria. There was also an outermost component (L3) composed of two to three layers that appeared to be detached and broken in some places (Fig. 2b).

The envelope of strain AG-3a $\mathrm{a}^{\mathrm{T}}$ consisted of a three-layered asymmetric cytoplasmic membrane surrounded by a gram-positive-like cell wall with an innermost highly electron-dense layer and an corrugated outer surface. Growth on solid medium was shown to produce a fibrous periodic acid-Schiffpositive capsular layer surrounding and interconnecting adjacent cells (Fig. 2c). This surface structure was not seen in bacteria grown in liquid medium.

The new slightly thermophilic Deinococcus spp. isolates had many biochemical characteristics in common, including the ability to hydrolyze proteins and Tween 40 , the ability to reduce tellurite $(0.1 \%, \mathrm{wt} / \mathrm{vol})$, and the ability to grow in the presence of $1 \%(\mathrm{wt} / \mathrm{vol}) \mathrm{NaCl}$, but several characteristics distinguished the two species (Table 1). These characteristics were primarily found in the assimilation of single carbon sources. Strains AG-3a ${ }^{\mathrm{T}}$, AG-5a, and RSPS-2a grew better in the minimal medium chosen for assessment of carbon source assimilation than strains ALT-1 $\mathrm{b}^{\mathrm{T}}$, RSG-1.2, and RSPS-7a and used a larger number of substrates. In fact, arginine was the only carbon source assimilated by strains ALT-1b ${ }^{\mathrm{T}}$, RSG-1.2, and RSPS-7 that was not utilized by AG-3a ${ }^{\mathrm{T}}$, AG-5a, and RSPS-2a. Strains ALT-1b ${ }^{\mathrm{T}}$, RSG-1.2, and RSPS-7a required yeast extract for growth, while strains $A G-3 a^{T}, A G-5 a$, and RSPS-2a did not.

Peptidoglycan analysis and polar lipid, quinone, and fatty acid compositions. The peptidoglycan of strains $A G-3 a^{T}$ and ALT $-1 b^{T}$ contained ornithine, glutamic acid, alanine, and glycine at a molar ratio of 1:1:2:2 to 3 . The results of the analysis of the partial hydrolysates of the peptidoglycan were compatible with type A3 $\beta$ (L-Orn-Gly ${ }_{2-3}$ ) defined by Schleifer and Kandler (47). The major respiratory lipoquinone of strains AG-3 ${ }^{\mathrm{T}}$, AG-5a, ALT-1 ${ }^{\mathrm{T}}$, and RSG-1.2 was menaquinone 8. The polar lipids of the strains of both new species were dominated by phosphoglycolipids. The strains of the species represented by strain AG-3at also had three glycolipids and two phosphoglycolipids that could not be detected in the strains of the species represented by strain ALT- $1 b^{\mathrm{T}}$ (Fig. 3).

Fatty acid methyl esters were separated by gas chromatography, and their identities were confirmed by gas chromatography-mass spectrometry (Table 2 ). The fatty acids of strains AG-3a ${ }^{\mathrm{T}}$, AG-4a, AG-5a, AG-6a, AG-7a, and RSPS-2a were dominated by $15: 0$ iso and $17: 0$ iso, while unsaturated fatty acids were minor components. Strains ALT-1b ${ }^{\mathrm{T}}$, RSG-1.2, RSPS-5a, RSPS-5c, and RSPS-7a, on the other hand, had large relative proportions of unsaturated fatty acids that accounted for more than $40 \%$ of the total fatty acids. However, the latter strains, in contrast to the former strains, had two slightly different fatty acid compositions, both of which were distinct from the fatty acid composition of the former strains. The predominant fatty acid of these strains had an equivalent chain length slightly shorter than that of methylhexadecanoic acid, and its molecular ion at $m / z 282$ was consistent with a monounsaturated heptadecanoic acid. The presence of fragment ions at $m / z 227,195$, and 177 identified this fatty acid as 15-methylhexadecanoic acid (17:1 iso) (2). The equivalent chain length of 16.419 was consistent with identification of this fatty acid as $17: 1 \omega 9 c$ iso. The majority of the type strains of the mesophilic species possessed large relative proportions of unsaturated fatty acids, and these proportions were especially high in Deinococcus grandis.

Radiation resistance. The survival curves of the type strain of Deinococcus radiodurans, AG-3a ${ }^{\mathrm{T}}$, and ALT- $1 \mathrm{~b}^{\mathrm{T}}$ had sigmoid shapes (Fig. 4). The shoulder doses (the doses required before reduction in the CFU) of the type strain of Deinococcus radiodurans and $\mathrm{ALT}-1 \mathrm{~b}^{\mathrm{T}}$ were 5.4 and $7.3 \mathrm{kGy}$, respectively. The doses required to reduce the number of viable units after the shoulder to $10 \%$ were 3.2 and $1.8 \mathrm{kGy}$, respectively. Strain $\mathrm{AG}-3 \mathrm{a}^{\mathrm{T}}$ was less resistant than the type strain of Deinococcus radiodurans and ALT- $1 \mathrm{~b}^{\mathrm{T}}$; the shoulder dose for this strain was about $3.7 \mathrm{kGy}$, and the dose required to reduce the number of viable units after the shoulder to $10 \%$ was $1.4 \mathrm{kGy}$.

16S rRNA gene sequence analysis. Full $16 \mathrm{~S}$ rDNA sequences that were 1,472 or 1,473 nucleotides long were determined for six of the isolates. An initial comparison of the $16 \mathrm{~S}$ rDNA sequences determined for strains AG-3a ${ }^{\mathrm{T}}, \mathrm{AG}-5 \mathrm{a}$, RSPS-2a, ALT- $1 b^{\mathrm{T}}$, RSG-1.2, and RSPS-7a with the sequences 

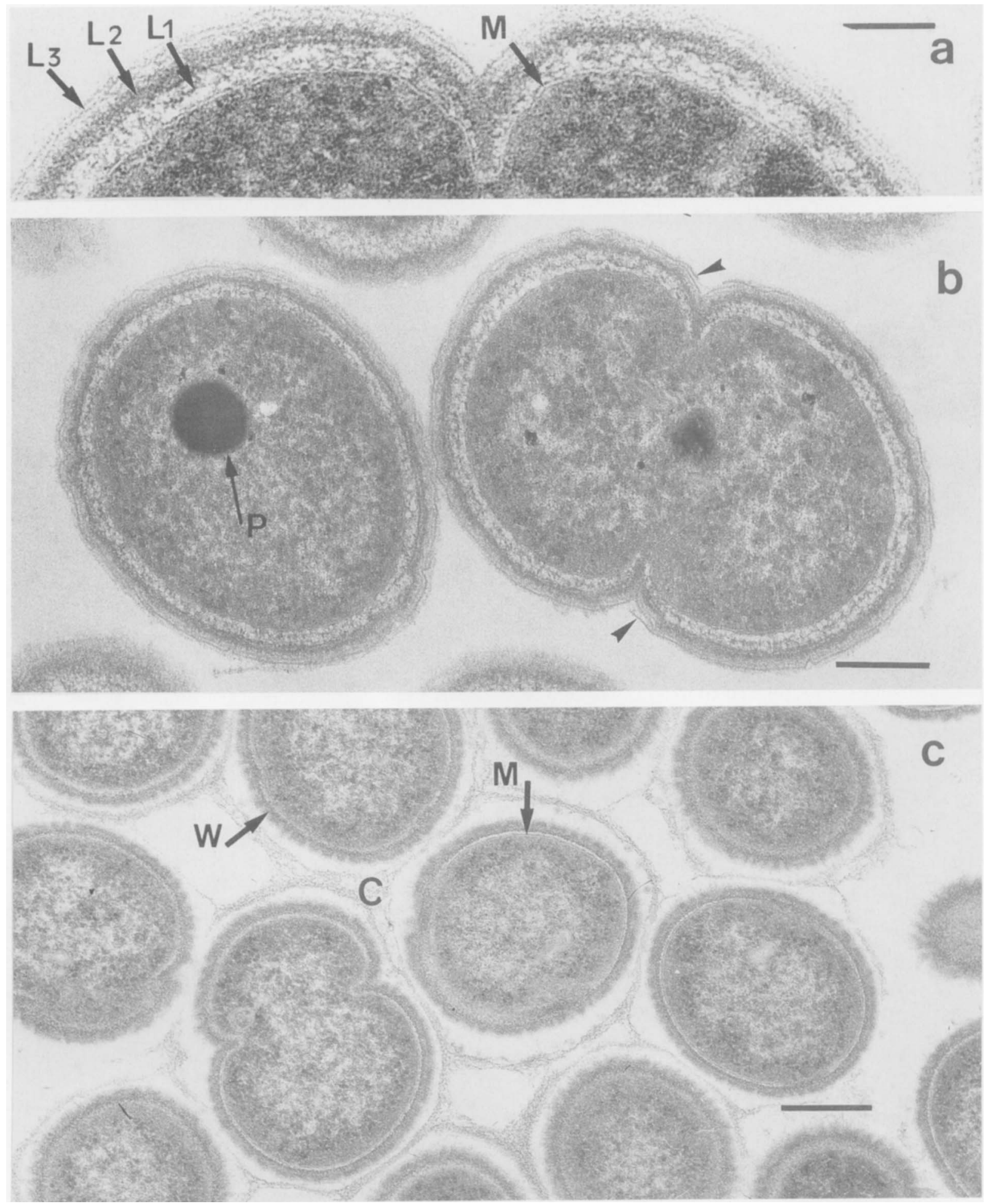

FIG. 2. Ultrastructure of strain ALT- $1 \mathrm{~b}^{\mathrm{T}}$ and AG-3a $\mathrm{a}^{\mathrm{T}}$ grown on solid medium. (a) Strain ALT-1 $\mathrm{b}^{\mathrm{T}}$, showing the cytoplasmic membrane (M) and wall structure composed of an innermost layer (L1), an intermediate layer presumably containing peptidoglycan (L2), and a multilayered external component (L3). Bar $=0.125 \mu \mathrm{m}$. (b) Strain ALT-1 $\mathrm{b}^{\mathrm{T}}$, showing cell division and polyphosphate inclusions $(\mathrm{P})$. The arrowheads indicate the presence of broken ends on the outermost layer $(\mathrm{L} 3)$. Bar $=0.25 \mu \mathrm{m}$. (c) Strain AG-3a ${ }^{\mathrm{T}}$, showing the membrane $(\mathrm{M})$, a corrugated cell wall with a high-density innermost layer $(\mathrm{W})$, and a fibrilar capsule-like structure $(\mathrm{C})$. Bar $=0.20 \mu \mathrm{m}$.

of representatives of the main bacterial lines of descent indicated that the former strains fell within the radiation of the Deinococcus-Thermus lineage. A more detailed analysis based on a data set comprising 1,406 unambiguous nucleotides be- tween positions 27 and 1530 (Escherichia coli positions [4]) showed that the new isolates are most closely related to members of the genus Deinococcus (Fig. 5). The six strains for which $16 \mathrm{~S}$ rDNA sequences were determined formed a new lineage 
TABLE 1. Biochemical and tolerance characteristics that distinguish the strains of the new species ${ }^{a}$

\begin{tabular}{|c|c|c|c|c|c|c|}
\hline Characteristic & $A G-3 a^{T}$ & AG-5a & RSPS-2a & ALT- $1 b^{T}$ & RSG-1.2 & RSPS-7a \\
\hline $\begin{array}{l}\text { Reduction of tellu- } \\
\text { rite }(0.5 \%)\end{array}$ & $+^{b}$ & + & + & - & - & - \\
\hline \multicolumn{7}{|l|}{ Hydrolysis of: } \\
\hline Starch & + & + & - & + & + & + \\
\hline Arbutin & + & + & + & - & - & - \\
\hline \multicolumn{7}{|l|}{ Presence of: } \\
\hline$\alpha$-Galactosidase & - & - & - & + & + & - \\
\hline$\beta$-Galactosidase & w & w & w & + & - & - \\
\hline \multicolumn{7}{|l|}{ Utilization of: } \\
\hline D-Cellobiose & + & + & + & - & - & - \\
\hline Lactose & + & + & - & - & - & - \\
\hline D-Galactose & + & + & + & - & - & - \\
\hline D-Mannose & + & + & + & + & - & + \\
\hline L-Rhamnose & + & + & - & - & - & - \\
\hline D-Xylose & + & + & + & - & - & - \\
\hline D-Mannitol & + & + & - & - & - & - \\
\hline D-Sorbitol & + & + & + & - & - & - \\
\hline L-Arginine & - & - & - & + & + & + \\
\hline L-Glutamine & + & + & + & + & - & + \\
\hline Malate & + & + & + & - & - & - \\
\hline Succinate & + & + & + & - & - & - \\
\hline
\end{tabular}

${ }^{a}$ All of the organisms hydrolyzed hide powder azure, casein, gelatin, hippurate, and Tween 40 , reduced tellurite $(0.1 \%$, wt/vol), and grew in the presence of $1 \%(\mathrm{wt} / \mathrm{vol}) \mathrm{NaCl}$ but not in the presence of $2 \% \mathrm{NaCl}$. Nitrate was not reduced. None of the strains hydrolyzed xylan or Tween 80 . D-Fructose, D-glucose, sucrose, D-trchalose, maltose, glycerol, L-asparagine, L-glutamate, L-proline, Lserine, and pyruvate were assimilated by all of the strains. None of the strains utilized D-raffinose, D-melibiose, L-arabinose, myo-inositol, ribitol, and citrate.

${ }^{b}+$, positive result or growth; - , negative result or no growth; w, weak positive result or growth.

comprised of two clusters. One cluster contained strains AG$3 \mathrm{a}^{\mathrm{T}}$, AG-5a, and RSPS-2a, while strains ALT-1b ${ }^{\mathrm{T}}$, RSG-1.2, and RSPS-7a formed the second cluster. The 16S rDNA sequence similarity values between the new isolates and the other Deinococcus species were in the range from 88.1 to $91.7 \%$. The $16 \mathrm{~S}$ rDNA sequence similarities to Thermus and Meiothermus species were less than $81 \%$. The $16 \mathrm{~S}$ rDNA sequence similarities between the two clusters of new isolates were in the range from 92.1 to $92.4 \%$, while within the clusters the similarity values ranged from 99.1 to $99.9 \%$ (data not shown).

$\mathbf{G}+\mathbf{C}$ content of the DNA. The $\mathrm{G}+\mathrm{C}$ contents determined for the new isolates are as follows: AG-3 $\mathrm{a}^{\mathrm{T}}, 65.9 \mathrm{~mol} \%$; RSPS- 2a, $67.8 \mathrm{~mol} \%$; ALT-1b ${ }^{\mathrm{T}}, 69.9 \mathrm{~mol} \%$; RSG-1.2, $70.6 \mathrm{~mol} \%$; and RSPS-7a, $70.0 \mathrm{~mol} \%$.

\section{DISCUSSION}

The results presented here clearly show that the isolates from hot springs at Agnano, Italy, and from central Portugal belong to two new species of the genus Deinococcus. The results of the $16 \mathrm{~S}$ rDNA sequence analysis show that the new isolates are members of the Thermus-Deinococcus lineage and fall within the radiation of the species comprising the Deinococcus lineage. These isolates represent two additional and distinct branches of the Deinococcus lineage, as reflected in the phylogenetic dendrogram and the $16 \mathrm{~S}$ rDNA sequence similarity values. The levels of $16 \mathrm{~S}$ rDNA sequence difference between the two strain clusters (7.6 to $7.9 \%)$ are within the range found between Deinococcus species (4.6 to 10.0\%) and, therefore, reflect the novel species status of the two clusters of new isolates (41). The $\mathrm{G}+\mathrm{C}$ values of the two new species are very high and within the range found for the other species of the genus Deinococcus, as well as species of the genera Thermus and Meiothermus (51).

The presence of ornithine in the peptidoglycan, the presence of menaquinone 8 as the major lipoquinone, the polar lipid pattern, and the fatty acid composition corroborate the results of the $16 \mathrm{~S}$ rDNA sequence analysis, showing that the new isolates are very closely related to the species of the genus Deinococcus. The fatty acids of the majority of the species of the genus Deinococcus are dominated by unsaturated fatty acids, although Deinococcus radiopugnans possesses large relative proportions of saturated branched-chain fatty acids (12). The major fatty acids of the species represented by the Agnano strains and strain RSPS-2a are saturated iso- and anteisobranched acids, while the levels of unsaturated fatty acids are very low. However, the low levels of unsaturated fatty acid in this species do not appear to reflect the high growth temperatures of the strains, since the strains of the other species have very high levels of unsaturated fatty acids.

The gamma radiation resistance of the type strains of the two new species shows that, at present, all species of the genus Deinococcus possess this characteristic. The radiation resistance values obtained in this study for Deinococcus radiodurans were comparable to those obtained previously for this organism $(32,33)$. The different radiation resistance of strains AG$3 \mathrm{a}^{\mathrm{T}}$ and $\mathrm{ALT}-1 \mathrm{~b}^{\mathrm{T}}$ may not reflect a taxonomic distinction between the two species, but may be due to differences among

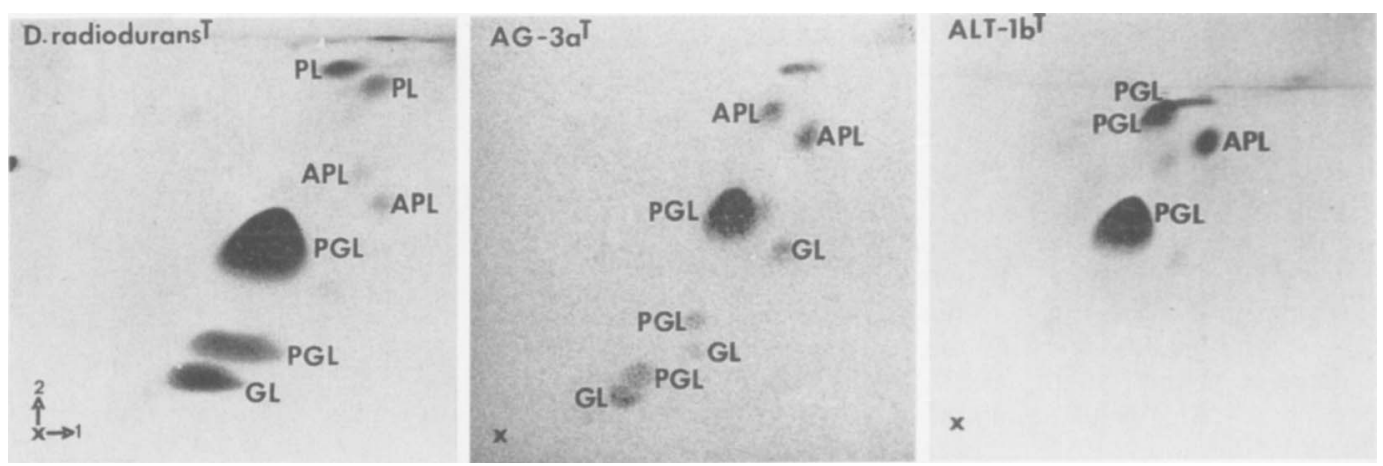

FIG. 3. Two-dimensional thin-layer chromatography of polar lipids of the type strain of Deinococcus radiodurans and strains AG-3a ${ }^{\mathrm{T}}$ and $\mathrm{ALT}-1 \mathrm{~b}^{\mathrm{T}}$. Components were visualized by staining with $5 \%$ molybdophosphoric acid in ethanol followed by heating of the plates at $160^{\circ} \mathrm{C}$. Abbreviations: PGL, phosphoglycolipid; GL, glycolipid; PL, phospholipid; APL, aminophospholipid. 
TABLE 2. Mean fatty acid compositions of the new species and of Deinococcus spp.

\begin{tabular}{|c|c|c|c|c|c|c|c|c|}
\hline \multirow[b]{2}{*}{ Fatty acid ${ }^{a}$} & \multicolumn{8}{|c|}{$\%$ in: } \\
\hline & $\begin{array}{l}\text { AG-3a }{ }^{\mathrm{T}} \text {, other } \\
\text { AG strains, } \\
\text { and RSPS- } 2 \mathrm{a}^{b}\end{array}$ & $\begin{array}{l}\text { ALT-1b }{ }^{\mathrm{T}} \\
\text { RSPS-7a, and } \\
\text { RSPS-5c }\end{array}$ & $\begin{array}{l}\text { RSG-1.2 and } \\
\text { RSPS-5a }\end{array}$ & $\begin{array}{c}\text { Deinococcus } \\
\text { grandis } \\
\text { DSM } 3963^{T}\end{array}$ & $\begin{array}{l}\text { Deinococcus } \\
\text { proteolyticus } \\
\text { DSM } 20540^{\mathrm{T}}\end{array}$ & $\begin{array}{l}\text { Deinococcus } \\
\text { radiodurans } \\
\text { DSM } 20539^{\mathrm{T}}\end{array}$ & $\begin{array}{l}\text { Deinococcus } \\
\text { radiophilus } \\
\text { DSM 20551 }^{\mathrm{T}}\end{array}$ & $\begin{array}{c}\text { Deinococcus } \\
\text { radiopugnans } \\
\text { ATCC } 19172^{\mathrm{T}}\end{array}$ \\
\hline $11: 0$ iso & & & $1.2 \pm 0.4^{c}$ & & & & & \\
\hline $12: 0$ iso & & & & & & & & \\
\hline $12: 0$ & & & & & & & $3.4 \pm 0.1$ & \\
\hline $13: 0$ iso & $7.7 \pm 2.9$ & & $1.0 \pm 0.5$ & & & & & $1.6 \pm 0.1$ \\
\hline $13: 0$ & & & & & & & $1.9 \pm 0.2$ & \\
\hline $14: 0$ iso & $1.7 \pm 0.6$ & & & & & & & \\
\hline $14: 0$ & & & & & & & $8.9 \pm 0.1$ & \\
\hline $15: 1$ iso $F$ & & $1.6 \pm 0.3$ & $2.4 \pm 0.5$ & & & & & $1.9 \pm 0.1$ \\
\hline $15: 0$ iso & $24.8 \pm 3.1$ & $8.4 \pm 1.2$ & $13.8 \pm 0.9$ & $5.6 \pm 0.3$ & & & & $18.3 \pm 0.6$ \\
\hline $15: 0$ anteiso & $1.4 \pm 0.5$ & & & & & & & \\
\hline $15: 1 \omega 8 c$ & & $2.0 \pm 0.6$ & $1.1 \pm 0.3$ & & $1.3 \pm 0.1$ & & $2.2 \pm 0.3$ & $3.5 \pm 0.1$ \\
\hline $15: 1 \omega 6 c$ & & $6.4 \pm 1.0$ & $3.2 \pm 0.3$ & $30.8 \pm 0.1$ & $5.1 \pm 1.3$ & $3.1 \pm 0.1$ & & $5.6 \pm 0.6$ \\
\hline $15: 0$ & $1.1 \pm 0.4$ & $8.5 \pm 1.6$ & $5.0 \pm 0.8$ & $18.1 \pm 0.3$ & $1.6 \pm 0.5$ & $3.4 \pm 0.4$ & $9.0 \pm 0.9$ & $12.0 \pm 0.9$ \\
\hline $16: 0$ iso & $6.1 \pm 3.0$ & & & $2.0 \pm 0.2$ & & & & \\
\hline Unknown $15.356^{d}$ & & & & & & $1.4 \pm 0.1$ & $2.6 \pm 0.1$ & \\
\hline $16: 1 \omega 9 c$ & & & & & $3.4 \pm 0.1$ & $2.9 \pm 0.1$ & $10.0 \pm 0.9$ & \\
\hline $16: 1 \omega 7 c$ & & $5.4 \pm 0.3$ & $4.3 \pm 0.8$ & $10.4 \pm 0.1$ & $27.9 \pm 0.1$ & $39.9 \pm 1.6$ & $14.5 \pm 0.3$ & $5.1 \pm 0.4$ \\
\hline $16: 1 \omega 5 c$ & $1.1 \pm 0.6$ & & & $1.3 \pm 0.1$ & & & & \\
\hline $16: 0$ & $6.4 \pm 0.3$ & $7.3 \pm 0.9$ & $7.9 \pm 0.9$ & $5.0 \pm 0.2$ & $3.2 \pm 1.0$ & $14.1 \pm 0.2$ & $25.8 \pm 1.1$ & $5.2 \pm 0.1$ \\
\hline $17: 1 \omega 9 c$ iso & & $19.9 \pm 2.1$ & $27.3 \pm 4.0$ & & $2.5 \pm 0.1$ & $1.1 \pm 0.1$ & & $21.2 \pm 0.5$ \\
\hline Peak $A^{e}$ & $1.9 \pm 1.0$ & & & & & & & \\
\hline $17: 0$ iso & $35.3 \pm 2.7$ & $11.6 \pm 1.8$ & $16.1 \pm 3.1$ & $2.8 \pm 0.1$ & $2.7 \pm 0.2$ & & & $8.1 \pm 0.6$ \\
\hline $17: 1 \omega 8 c$ & & $9.3 \pm 1.5$ & $4.4 \pm 0.7$ & $2.1 \pm 0.4$ & $27.1 \pm 1.0$ & $11.8 \pm 0.4$ & $9.1 \pm 0.2$ & $5.8 \pm 0.2$ \\
\hline $17: 1 \omega 6 c$ & & $3.4 \pm 0.6$ & $1.7 \pm 0.2$ & $6.5 \pm 0.2$ & $8.8 \pm 1.2$ & $8.7 \pm 0.1$ & & \\
\hline $17: 0$ cyclo & $1.1 \pm 0.5$ & & & & & & & $1.1 \pm 0.1$ \\
\hline $17: 0$ & $2.3 \pm 0.6$ & $10.4 \pm 1.3$ & $5.6 \pm 1.2$ & $8.7 \pm 0.1$ & $4.3 \pm 1.1$ & $5.4 \pm 0.3$ & $5.2 \pm 0.5$ & $5.2 \pm 0.1$ \\
\hline $18: 0$ iso & $1.5 \pm 1.0$ & & & & & & & \\
\hline Unknown $17.654^{f}$ & & & & & $3.6 \pm 0.1$ & & & \\
\hline $18: 1 \omega 9 c$ & & & & & $3.5 \pm 0.4$ & $1.3 \pm 0.2$ & $3.3 \pm 0.4$ & \\
\hline Peak B ${ }^{g}$ & & & & & $4.0 \pm 0.4$ & $3.6 \pm 0.5$ & & \\
\hline
\end{tabular}

${ }^{a}$ Data for several fatty acids that were present at levels of less than $1 \%$ in all strains are not shown.

${ }^{b}$ The other AG strains are strains AG-4a, AG-5a, AG-6a, and AG-7a.

${ }^{c}$ The values are the means \pm standard deviations from at least two determinations for each strain.

${ }^{d}$ Unknown fatty acids or alcohol with an equivalent chain length of 15.356

${ }^{e}$ This peak contains $17: 1$ iso I or 17:1 anteiso B.

${ }^{f}$ Unknown fatty acids or alcohol with an equivalent chain length of 17.654

${ }^{g}$ This peak contains $18: 1 \omega 7 c$ or $18: 1 \omega 9 t$ or $18: 1 \omega 12 t$.

strains, as was shown for several strains assigned to Deinococcus radiopugnans (28).

Other radiation-resistant bacteria unrelated to Deinococcus spp. are known; these include Rubrobacter radiotolerans (50, 56), Acinetobacter radioresistens (34), and Methylobacterium radiotolerans (16). To our knowledge, $R$. radiotolerans is the only radiation-resistant species previously isolated from a hot spring that, interestingly, was described as radioactive $(50,56)$. Strains similar to this species and to Rubrobacter xylanophilus, originally isolated from a thermally polluted effluent (6), have also been isolated recently from the hot spring at São Pedro do Sul after gamma radiation of the samples, leading to speculation that some radiation-resistant species can be found in hot springs (15).

This is the first report of isolation of species of the genus Deinococcus from hot springs. Moreover, it is interesting to note that the species represented by strains $A G-3 a^{T}$ and AG-5a is slightly acidophilic, and most of the strains of this species were isolated from the hot springs at Agnano, where the $\mathrm{pH}$ is about 6.5 , while slightly alkaliphilic strains ALT $-1 \mathrm{~b}^{\mathrm{T}}$, RSPS-7a, RSPS-5a, RSPS-5c, and RSG-1.2 of the other species were isolated from alkaline hot springs in Portugal. The most intriguing aspect, however, was the isolation of strain RSPS-2a from a Portuguese site with $\mathrm{pH}$ values of about 8.6 , leading to speculation that slightly acidophilic strains can colonize microenvironments of alkaline hot springs, such as biofilms, where the $\mathrm{pH}$ is lowered by other organisms.

The phylogenetic relationships among some Deinococcus

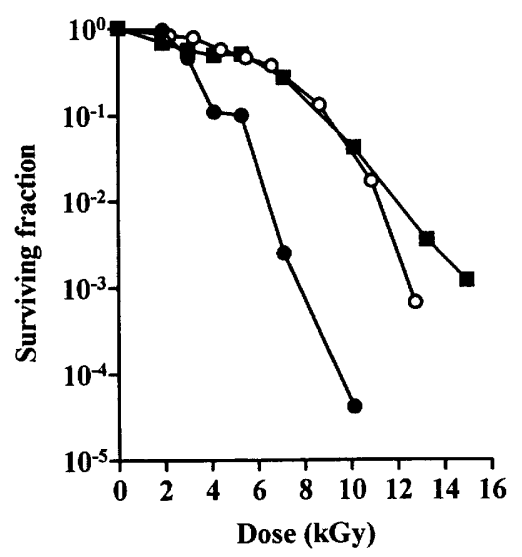

FIG. 4. Gamma radiation survival curves of strains $A G-3 a^{\mathrm{T}}(\bullet)$ and ALT$1 b^{\mathrm{T}}(\mathrm{O})$ and the type strain of Deinococcus radiodurans $(\boldsymbol{\square})$. 


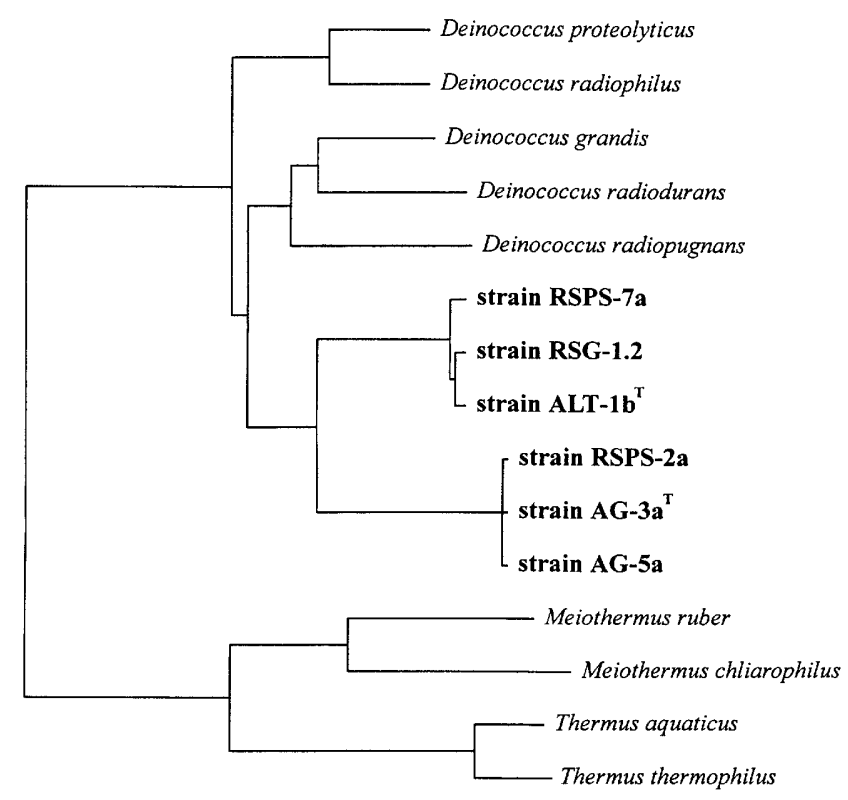

$5 \%$

FIG. 5. 16S rDNA-based phylogenetic dendrogram reconstructed from evolutionary distances by using the neighbor-joining method (45). The scale bar represents 5 inferred nucleotide substitutions per 100 nucleotides.

species, Deinobacter grandis (reclassified as Deinococcus grandis [41]), and species of the genera Thermus and Meiothermus have been demonstrated previously by $16 \mathrm{~S}$ rRNA catalog data (17) and full $16 \mathrm{~S}$ rRNA-rDNA sequence analyses $(13,35,53)$. The recent phylogenetic study of Rainey et al. (41) demonstrated that all species of the genus Deinococcus except the misclassified organism Deinococcus erythromyxa (now Kocuria erythromvxa) are phylogenetically related and from a sister lineage to that comprised of the species of the genera Thermus and Meiothermus. The stability of the relationship between these two lineages was substantiated by a full phylogenetic analysis and testing of the robustness of the phylogenetic dendrograms by bootstrap analyses (41). Until the isolation of the strains described in this study, the Deinococcus branch of the Deinococcus-Thermus lineage contained only mesophilic organisms, while the Thermus-Meiothermus branch was exclusively composed of thermophilic strains. The Deinococcus lineage now comprises both mesophilic and slightly thermophilic representatives, a situation seen in other main lineages of the Bacteria, such as the spirochetes (39), the clostridia (42), the bacilli (40), and the green nonsulfur bacteria (55). Such mixed lineages are in contrast to the deeply branching lineages whose representatives are exclusively thermophilic or slightly thermophilic, such as the order Thermotogales (18), the order Aquificales (5), the genus Dictyoglomus (25), and the genus Coprothermobacter (38). The grouping of thermophilic strains with the Deinococcus-Thermus lineage also provides support at the physiological level for the phylogenetic relationship among members of the genera Deinococcus, Thermus, and Meiothermus.

On the basis of the results presented in this study, the species Deinococcus geothermalis is proposed for strains $\mathrm{AG}-3 \mathrm{a}^{\mathrm{T}}$, AG-5a, and RSPS-2a and the species Deinococcus murrayi is proposed for strains ALT-1b ${ }^{\mathrm{T}}$, RSG-1.2, and RSPS-7a.

Description of Deinococcus geothermalis sp. nov. Deinococcus geothermalis (ge.o.ther.ma'lis. Gr. n. geia, earth; Gr. adj. ther- mos, hot; M. L. adj. geothermalis, of hot springs). Deinococcus geothermalis strains form spherical cells 1.2 to $2.0 \mu \mathrm{m}$ in diameter. Cells dividing as tetrads are very common. Gram stain positive. The cells are nonmotile, and spores are not formed. Colonies on Degryse medium 162 are orange pigmented and $0.2 \mathrm{~mm}$ in diameter after $72 \mathrm{~h}$ of growth. Growth occurs between 30 and $55^{\circ} \mathrm{C}$ in Degryse medium 162; the optimum growth temperature for strain $\mathrm{AG}-3 \mathrm{a}^{\mathrm{T}}$ is about $47^{\circ} \mathrm{C}$. The optimum $\mathrm{pH}$ is about 6.5; growth does not occur at $\mathrm{pH} 4.0$ or 9.0. Yeast extract is not required for growth. The major fatty acids are 17:0 iso and 15:0 iso; unsaturated fatty acids are present in low relative proportions. Oxidase and catalase positive. Nitrate is not reduced to nitrite. $\alpha$-Galactosidase negative and $\beta$-galactosidase positive. Strain $A G-3 a^{T}$ degrades casein, gelatin, hide powder azure, hippurate, arbutin, and starch. Strain RSPS-2a does not degrade starch. Strain AG-3aT utilizes D-cellobiose, D-trehalose, lactose, maltose, D-fructose, D-galactose, D-glucose, D-mannose, L-rhamnose, sucrose, Dxylose, D-mannitol, D-sorbitol, glycerol, L-asparagine, L-glutamate, L-glutamine, L-proline, L-serine, malate, pyruvate, and succinate. Strain RSPS-2a utilizes all of these compounds except lactose, L-rhamnose, and D-mannitol. The strains do not utilize D-raffinose, D-melibiose, L-arabinose, myo-inositol, ribitol, L-arginine, and citrate. Strain AG- $3 \mathrm{a}^{\mathrm{T}}$ is extremely radiation resistant.

The DNA of strain AG- $3 \mathrm{a}^{\mathrm{T}}$ has a $\mathrm{G}+\mathrm{C}$ content of 65.9 mol\%. This bacterium was isolated from the hot spring at Agnano, Naples, Italy. Strain AG-3a ${ }^{\mathrm{T}}$ has been deposited in the Deutsche Sammlung von Mikroorganismen und Zellkulturen, Braunschweig, Germany, as strain DSM $11300^{\mathrm{T}}$. Strains AG-5a (= DSM 11301) and RSPS-2a (= DSM 11302) are reference strains of this species.

Description of Deinococcus murrayi sp. nov. Deinococcus murrayi (mur'ray.i. L. gen. n. murrayi, of Murray, named after the Canadian microbiologist R. G. E. Murray in recognition of his research on the genus Deinococcus). Deinococcus murrayi strains form spherical cells 1.2 to $2.0 \mu \mathrm{m}$ in diameter. Cells dividing as tetrads are very common. Gram stain positive. The cells are nonmotile, and spores are not formed. Colonies on Degryse medium 162 are orange pigmented and $0.2 \mathrm{~mm}$ in diameter after $72 \mathrm{~h}$ of growth. Growth occurs between 30 and $52.5^{\circ} \mathrm{C}$ in Degryse medium 162 ; the optimum growth temperature for strain ALT- $1 b^{\mathrm{T}}$ is about $47^{\circ} \mathrm{C}$. The optimum $\mathrm{pH}$ is about 8.0; growth does not occur at $\mathrm{pH} 5.0$ or 10.5. Yeast extract is required for growth. The major fatty acids are 17:1 $\omega 9 \mathrm{c}$ iso and 17:0 iso. Oxidase and catalase positive. Nitrate is not reduced to nitrite. $\alpha$-Galactosidase and $\beta$-galactosidase positive. Strain RSPS-7a is $\alpha$-galactosidase negative, and strains RSG-1.2 and RSPS-7a are $\beta$-galactosidase negative. Casein, gelatin, hide powder azure, hippurate, and starch are degraded. Strains ALT-1 $b^{T}$ and RSPS-7a utilize D-trehalose, maltose, D-fructose, D-glucose, D-mannose, sucrose, glycerol, L-arginine, L-asparagine, L-glutamate, L-glutamine, L-proline, L-serine, and pyruvate. Strain RSG-1.2 does not utilize two of these compounds, D-mannose and L-glutamine. None of the strains utilizes D-raffinose, D-cellobiose, D-melibiose, lactose, D-galactose, L-rhamnose, D-xylose, L-arabinose, D-mannitol, D-sorbitol, myo-inositol, ribitol, citrate, malate, and succinate. Strain ALT $-1 b^{T}$ is extremely radiation resistant.

The DNA of strain ALT $-1 b^{\mathrm{T}}$ has a $\mathrm{G}+\mathrm{C}$ content of 69.9 mol\%. This bacterium was isolated from the hot spring at Alcafache in central Portugal. Strain ALT- $1 b^{T}$ has been deposited in the Deutsche Sammlung von Mikroorganismen und Zellkulturen, Braunschweig, Germany, as strain DSM $11303^{\mathrm{T}}$. Strains RSG-1.2 (= DSM 11304) and RSPS-7a (= DSM $11305)$ are reference strains of this species. 


\section{ACKNOWLEDGMENTS}

This work was supported by Commission of European Communities Biotech Program (Biotechnology of Extremophiles) contract BIO2CT93-0274 and by Praxis XXI Program grant Praxis 2/2.1/BIO/20/94. A.C.F. was supported by Praxis XXI Program grant Praxis BD/3406/94.

We are indebted to Hans G. Trüper (University of Bonn, Bonn, Germany) for his advice concerning the names of the organisms, Norbert Weiss (Deutsche Sammlung von Mikroorganismen und Zellkulturen, Braunschweig, Germany) for performing the cell wall analysis, and Paula M. Macedo and M. Irene Barros (Centro de Citologia Experimental, Porto, Portugal) for the electron microscopy. We also thank Luisa Botelho (Unidade de Tecnologia da Radiação, Sacavém, Portugal) for assistance provided during the gamma irradiation of the water samples and strains.

\section{REFERENCES}

1. Anderson, A. W., H. C. Nordan, R. F. Cain, G. Parrish, and D. Duggan. 1956. Studies on a radio-resistant micrococcus. $I$. The isolation, morphology, cultura! characteristics and resistance to gamma radiation. Food Technol. 10: $575-577$

2. Boon, J. J., B. Van De Graaf, P. J. W. Schuyl, F. De Lange, and J. W. De Leeuw. 1977. The mass spectrometry of iso and anteiso monoenoic fatty acids. Lipids 12:717-721.

3. Brooks, B. W., and R. G. E. Murray. 1981. Nomenclature for "Micrococcus radiodurans" and other radiation-resistant cocci: Deinococcaceae fam. nov. and Deinococcus gen. nov., including five species. Int. J. Syst. Bacteriol. 31:353-360.

4. Brosius, J., J. L. Palmer, J. P. Kennedy, and H. F. Noller. 1978. Complete nucleotide sequence of a $16 \mathrm{~S}$ ribosomal RNA gene from Escherichia coli. Proc. Natl. Acad. Sci. USA 75:4801-4805.

5. Burggraf, S., G. J. Olsen, K. O. Stetter and C. R. Woese. 1992. A phylogenetic analysis of Aquifex pyrophilus. Syst. Appl. Microbiol. 15:352-356.

6. Carreto, L., E. Moore, M. F. Nobre, R. Wait, P. W. Riley, R. J. Sharp, and M. S. da Costa. 1996. Rubrobacter xylanophilus sp. nov., a new thermophilic species isolated from a thermally polluted effluent. Int. J. Syst. Bacteriol. 46:460-465.

7. Cashion, P., M. A. Holder-Franklin, J. McCully, and M. Franklin. 1977. A rapid method for the base ratio determination of bacterial DNA. Anal. Biochem. 81:461-466.

8. Davis, N. S., G. J. Silverman, and E. B. Masurovsky. 1963. Radiationresistant, pigmented coccus isolated from haddock tissue. J. Bacteriol. 86: 294-298.

9. Jegryse, E., N. Glansdorff, and A. Piérard. 1978. A comparative analysis of extreme thermophilic bacteria belonging to the genus Thermus. Arch. Microbiol. 117:189-196.

10. Deutsche Sammlung von Mikroorganismen und Zellkulturen. 1993. DSM catalogue of strains. Deutsche Sammlung von Mikroorganismen und Zellkulturen, Braunschweig, Germany.

11. Donato, M. M., E. A. Seleiro, and M. S. da Costa. 1990. Polar lipid and fatty acid composition of strains of the genus Thermus. Syst. Appl. Microbiol. 13:234-239.

12. Embley, T. M., A. G. O'Donnell, R. Wait, and J. Rostron. 1987. Lipid and cell wall amino acid composition in the classification of members of the genus Deinococcus. Syst. Appl. Microbiol. 10:20-27.

13. Embley, T. M., R. H. Thomas, and R. A. D. Williams. 1993. Reduced thermophilic bias in the $16 \mathrm{~S}$ rDNA sequence from Thermus nuber provides further support for a relationship between Thermus and Deinococcus. Syst. Appl. Microbiol. 16:25-29.

14. Felsenstein, J. 1993. PHYL.IP (phylogenetic inference package), version 3.5.1. Department of Genetics, University of Washington, Seattle.

15. Ferreira, A. C., M. F. Nobre, and M. S. da Costa. Unpublished data.

16. Green, P. N., and I. J. Bousfield. 1983. Emendation of Methylobacterium Patt, Cole and Hanson 1976; Methylobacterium rhodinum (Heumann 1962) comb. nov. corrig.; Methylobacterium radiotolerans (Ito and Iizuka 1971) comb. nov. corrig.; and Methylobacterium mesophilicum (Austin and Goodfellow 1979) comb. nov. Int. J. Syst. Bacteriol. 33:875-877.

17. Hensel, R., W. Demharter, O. Kandler, R. M. Kroppenstedt, and E. Stackebrandt. 1986. Chemotaxonomic and molecular-genetic studies of the genus Thermus: evidence for a phylogenetic relationship of Thermus aquaticus and Thermus ruber to the genus Deinococcus. Int. J. Syst. Bacteriol, 36:444-453.

18. Huber, R., C. R. Woese, T. A. Langworthy, H. Fricke, and K. O. Stetter. 1989. Thermosipho africanus gen. nov. represents a new genus of thermophilic eubacteria within the "Thermotogales." Syst. Appl. Microbiol. 12:32-37.

19. Ito, H. 1977. Isolation of Micrococcus radiodurans occurring in radiodurised sawdust culture media of mushrooms. Agric. Biol. Chem. 41:35-41.

20. Ito, H., H. Watanabe, N. Takehisa, and H. Iizuka. 1983. Isolation and identification of radiation-resistant cocci belonging to the genus Deinococcus from sewage sludges and animal feeds. Agric. Biol. Chem. 47:1239-1247.

21. Jukes, T. H., and C. R. Cantor. 1969. Evolution of protein molecules, p.
21-132. In H. N. Munro (ed.), Mammalian protein metabolism. Academic Press, New York, N.Y.

22. Kobatake, M., S. Tamabe, and S. Hasegawa. 1973. Nouveau micrococcus radioresistant à pigment rouge, isolé de féces de Lama glama, et son utilisation comme indicateur microbiologique de la radio-sterilisation. C. R. Soc. Biol. 167:1506-1510.

23. Kuykendall, L. D., M. A. Roy, J. J. O'Neill, and T. E. Devine. 1988. Fatty acids, antibiotic resistance, and deoxyribonucleic acid homology groups of Bradyrhizobium japonicum. Int. J. Syst. Bacteriol. 38:358-361.

24. Lewis, N. F. 1973. Radio-resistant Micrococcus radiophilus sp. nov. isolated from irradiated Bombay duck (Harpodon nehereus). Curr. Sci. 42:504.

25. Love, C. A., B. K. C. Patel, W. Ludwig, and E. Stackebrandt. 1993. The phylogenetic position of Dictyoglomus thermophilum based on 16S rRNA sequence analysis. FEMS Microbiol. Lett. 107:317-320.

26. Maidak, B. L., N. Larsen, M. J. McCaughey, R. Overbeek, G. J. Olsen, K. Fogel, J. Blandy, and C. R. Woese. 1994. The Ribosomal Database Project. Nucleic Acids Res. 22:3485-3487.

27. Manaia, C. M., and M. S. da Costa. 1991. Characterization of halotolerant Thermus isolates from shallow marine hot springs on S. Miguel, Azores. J. Gen. Microbiol, 137:2643-2648.

28. Masters, C. I., R. G. E. Murray, B. E. B. Moseley, and K. W. Minton. 1991 DNA polymorphisms in new isolates of 'Deinococcus radiopugnans.' J. Gen. Microbiol. 137:1459-1469.

29. Mattimore, V., and J. R. Battista. 1996. Radioresistance of Deinococcus radiodurans: functions necessary to survive ionizing radiation are also necessary to survive prolonged desiccation. J. Bacteriol. 178:633-637.

30. Mesbah, M., U. Premachandran, and W. B. Whitman. 1989. Precise measurement of the $\mathrm{G}+\mathrm{C}$ content of deoxyribonucleic acid by high-performance liquid chromatography. Int. J. Syst. Bacteriol. 39:159-167.

31. Minton, K. W. 1994. DNA repair in the extremely radioresistant bacterium Deinococcus radiodurans. Mol. Microbiol. 13:9-15.

32. Moseley, B. E. B. 1967 . The isolation and some properties of radiationsensitive mutants of Micrococcus radiodurans. J. Gen. Microbiol. 49:293-300.

33. Moseley, B. E. B., and A. Mattingly. 1971. Repair of irradiated transforming deoxyribonucleic acid in wild-type and a radiation-sensitive mutant of $\mathrm{Mi}$ crococcus radiodurans. J. Bacteriol. 105:976-983.

34. Nishimura, Y., T. Ino, and H. Iisuka. 1988. Acinetobacter radioresistens sp. nov. isolated from cotton and soil. Int. J. Syst. Bacteriol. 38:209-211.

35. Nobre, M. F., H. G. Trüper, and M. S. da Costa. 1996. Transfer of Thermus ruber (Loginova et al., 1984), Thermus silvanus (Tenreiro et al., 1995), and Thermus chliarophilus (Tenreiro et al., 1995) to Meiothermus gen. nov. as Meiothermus ruber comb. nov., Meiothermus silvanus comb. nov., and Meiothermus chliarophilus comb. nov., respectively, and emendation of the genus Thermus. Int. J. Syst. Bacteriol. 46:604-606.

36. Oyaizu, H., E. Stackebrandt, K. H. Schleifer, W. Ludwig, H. Pohla, H. Ito, A. Hirata, Y. Oyaizu, and K. Komagata. 1987. A radiation-resistant rod-shaped bacterium, Deinobacter grandis gen. nov., sp. nov., with peptidoglycan containing ornithine. Int. J. Syst. Bacteriol. 37:62-67.

37. Prado, A., M. S. da Costa, and V. M. C. Madeira. 1988. Effect of growth temperature on the lipid composition of two strains of Thermus sp. J. Gen. Microbiol. 134:1653-1660.

38. Rainey, F. A., and E. Stackebrandt. 1993. Transfer of the type species of the genus Thermobacteroides to the genus Thermoanaerobacter as Thermoanaerobacter acetoethylicus (Ben-Bassat and Zeikus 1981) comb. nov., description of Coprothermobacter gen. nov., and reclassification of Thermobacteroides proteolyticus as Coprothermobacter proteolyticus (Ollivier et al. 1985) comb. nov. Int. J. Syst. Bacteriol. 43:857-859.

39. Rainey, F. A., M. Dorsch, H. W. Morgan, and E. Stackebrandt. 1992. 16S rDNA analysis of Spirochaeta thermophila: its phylogenetic position and implications for the systematics of the order Spirochaetales. Syst. Appl. Microbiol. 15:197-202.

40. Rainey, F. A., D. Fritze, and E. Stackebrandt. 1994. The phylogenetic diversity of thermophilic members of the genus Bacillus as revealed by $16 \mathrm{~S} \mathrm{rDNA}$ analysis. FEMS Microbiol. Lett. 115:205-212.

41. Rainey, F. A., M. F. Nobre, P. Shumann, E. Stackebrandt, and M. S. da Costa. 1997. Phylogenetic diversity of the deinococci as determined by $16 \mathrm{~S}$ ribosomal DNA sequence comparison. Int. J. Syst. Bacteriol. 47:510-514.

42. Rainey, F. A., N. L. Ward, H. W. Morgan, R. Toalster, and E. Stackebrandt. 1993. Phylogenetic analysis of anaerobic thermophilic bacteria: aid for their reclassification. J. Bacteriol. 175:4772-4779.

43. Rainey, F. A., N. Ward-Rainey, R. M. Kroppenstedt, and E. Stackebrandt. 1996. The genus Nocardiopsis represents a phylogenetically coherent taxon and a distinct actinomycete lineage: proposal of Nocardiopsaceae fam. nov. Int. J. Syst. Bacteriol. 46:1088-1092.

44. Reasoner, D. J., and E. E. Geldreich. 1985. A new medium for the enumeration and subculture of bacteria from potable water. Appl. Environ. Microbiol. 49:1-7.

45. Saitou, N., and M. Nei. 1987. The neighbor-joining method: a new method for reconstructing phylogenetic trees. Mol. Biol. Evol, 4:406-425.

46. Santos, M. A., R. A. D. Williams, and M. S. da Costa. 1989. Numerical taxonomy of Thermus isolates from hot springs in Portugal. Syst. Appl. Microbiol. 12:310-315. 
47. Schleifer, K.-H., and O. Kandler. 1972. Peptidoglycan types of bacterial cell walls and their taxonomic implications. Bacteriol. Rev. 36:407-477.

48. Silva, M. T., and J. C. F. Sousa. 1973. Ultrastructure of the cell wall and cytoplasmic membrane of gram-negative bacteria with different fixation techniques. J. Bacteriol. 113:953-962.

49. Silva, M. T., and P. M. Macedo. 1987. Improved Thiéry staining for the ultrastructural detection of polysaccharides. J. Submicrosc. Cytol. 19:677681.

50. Suzuki, K., M. D. Collins, E. Iijima, and K. Komagata. 1988. Chemotaxonomic characterization of a radiotolerant bacterium, Arthrobacter radiotolerans: description of Rubrobacter radiotolerans gen. nov., comb. nov. FEMS Microbiol. Lett. 52:33-40.

51. Tenreiro, S., M. F. Nobre, and M. S. da Costa. 1995. Thermus silvanus sp. nov. and Thermus chliarophilus sp. nov., two new species related to Thermus ruber but with lower growth temperatures. Int. J. Syst. Bacteriol. 45:633-639.

52. Tindall, B. J. 1989. Fully saturated menaquinones in the archaebacterium Pyrobaculum islandicum. FEMS Microbiol. Lett. 60:251-254.

53. Weisburg, W. G., S. J. Giovanonni, and C. R. Woese. 1989. The DeinococcusThermus phylum and the effect of rRNA composition on phylogenetic tree construction. Syst. Appl. Microbiol. 11:128-134.

54. Williams, R. A. D., and M. S. da Costa. 1992. The genus Thermus and related microorganisms, p. 3745-3753. In A. Balows, H. G. Trüper, M. Dworkin, W. Harder, and K. H. Schleifer (ed.), The prokaryotes, 2nd ed. Springer-Verlag, New York, N.Y.

55. Woese, C. R. 1987. Bacterial evolution. Microbiol. Rev. 51:221-271.

56. Yoshinaka, T., K. Yano, and H. Yamaguchi. 1973. Isolation of a highly radioresistant bacterium, Arthrobacter radiotolerans nov. sp. Agric. Biol. Chem. 37:2269-2275. 